\title{
تأثير التناغم بين التغيير والسكون على الإنسان في الفراغات الداخلية
}

إعلاد
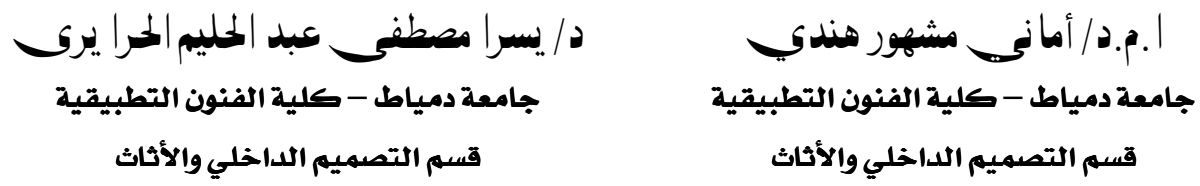

مجلة بحوث التربية النوعية ـ جامعة المنصورة

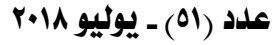




\title{
تأثير التناغم بين التغيير والسكون على الإنسان في الفراغات الداخلية
}

إعداد

\author{
د. ـ ـسرا مصطف عبد الحليم الحرايرى
}

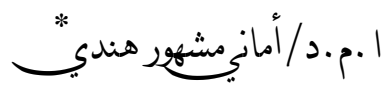

unil|

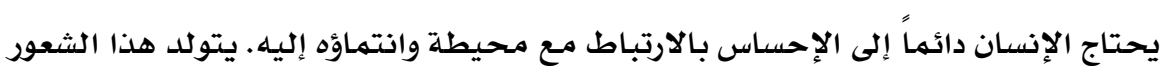

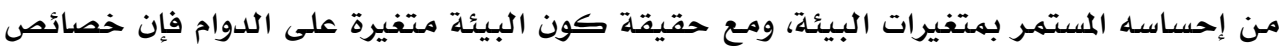

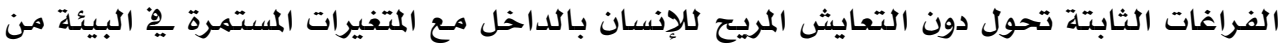

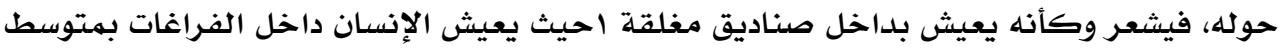

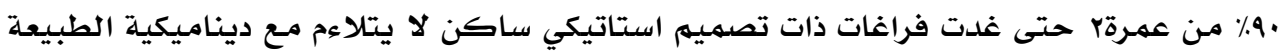
الإنسانية سريعة التغيير.

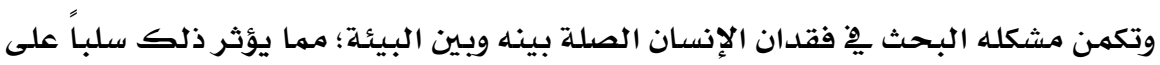

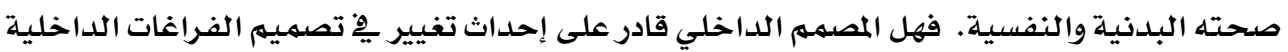

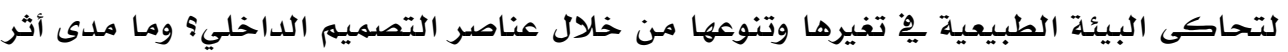

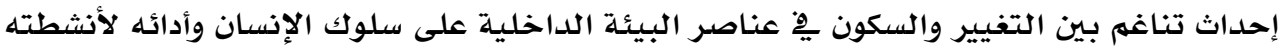

داخل الفراغ؟

فيهدف البحث إلى التنبؤ بما وراء التغيير والسكون ِِّ علاقة الفراغات الداخلية بالبيئة

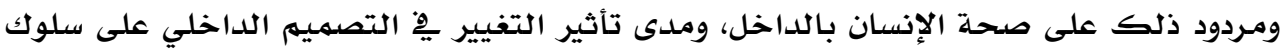

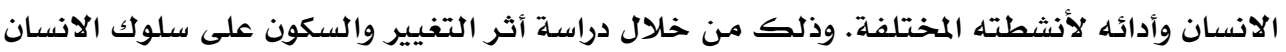

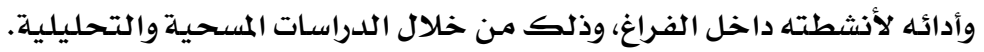
الكلمات المفتاحية: التغيير - السكون - الفراغ الداخلي - الراحة النفسية والبدنية.

المقدهة:

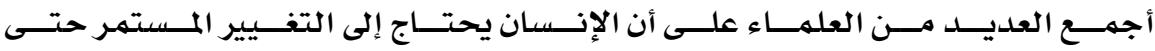

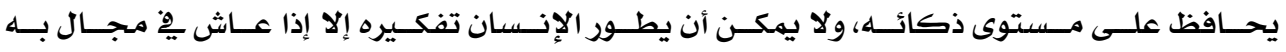

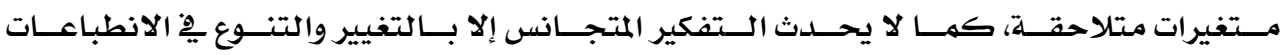

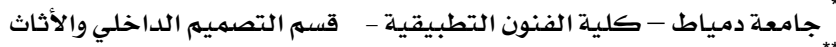

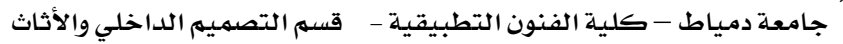

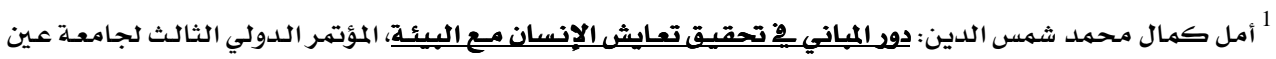

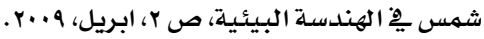

$$
\begin{aligned}
& \text { 2 المرجـع السابق، ص r }
\end{aligned}
$$




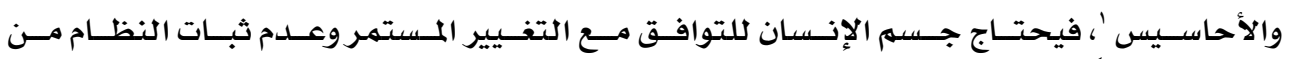

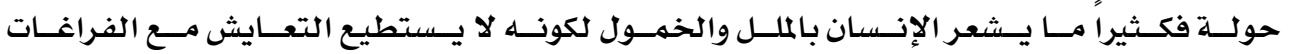

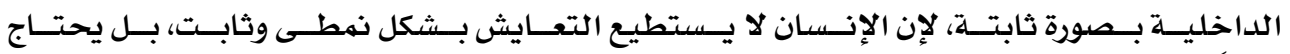
دائماً إلى التجديد والتطوير للحفاظ على حيويته ونشاطه وتحسين حالته الإنه النفسية.

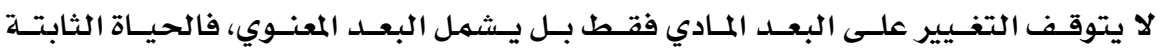

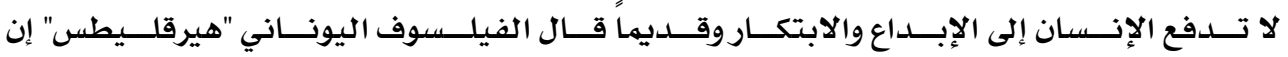

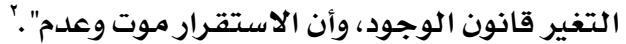

\section{التغيسيز والذزهن:}

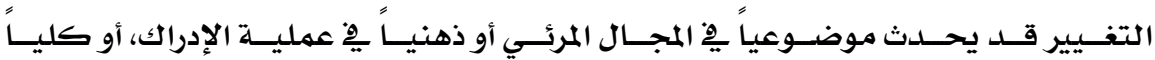

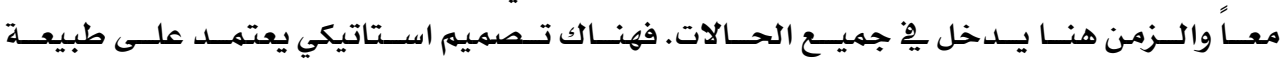

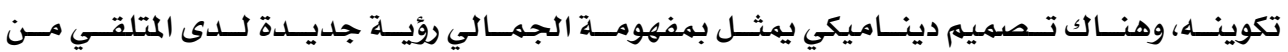

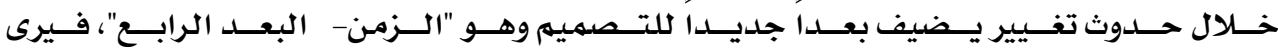

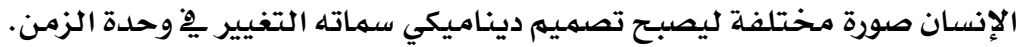

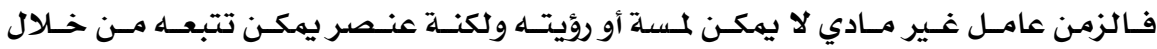

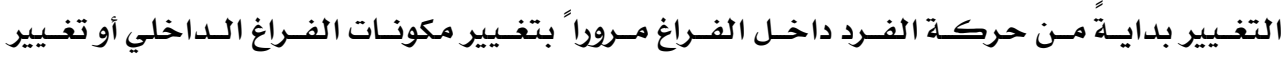

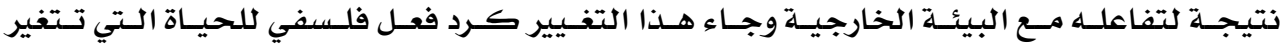

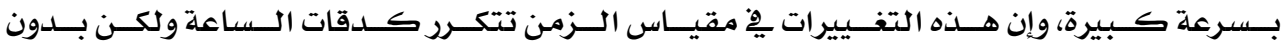
اتجاه.

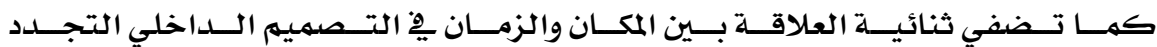

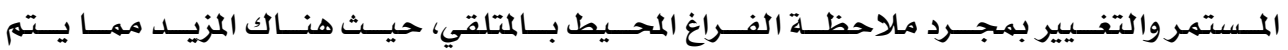

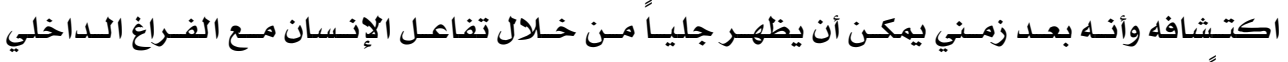

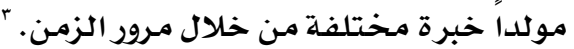

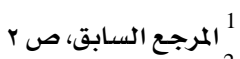
2 أحمد سمير - دينا فكرى : ثقافة التغيير كحافز إبداعي 2 التصميم الداخلي، التصميم الدولي، عدد 0، إصدار 1، ص " وائل رأفت محمود : ثنائية الزمان والمكان فح التصميم الداخلي "الحيز الداخلي للعمارة الإسلامية بين التأثير والتأثر"،

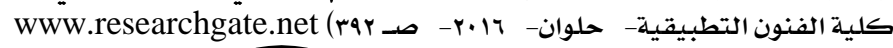




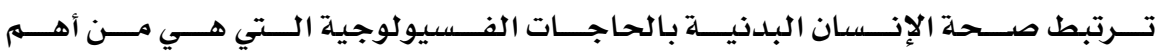

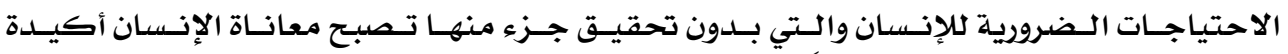

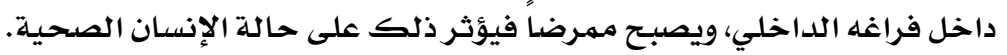

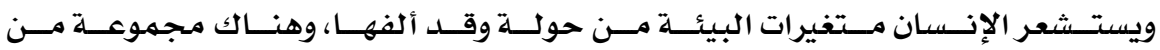

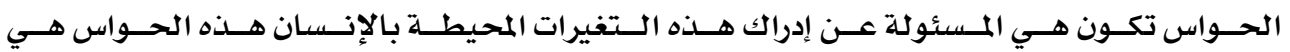

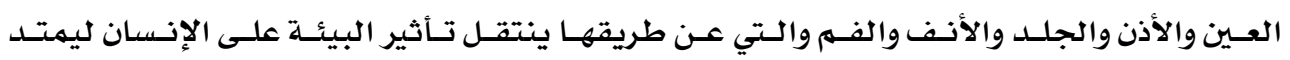

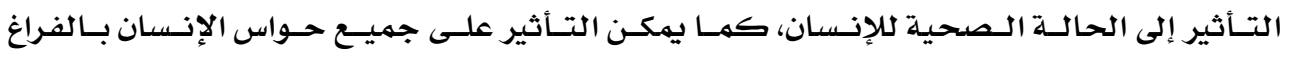

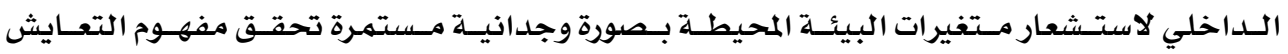

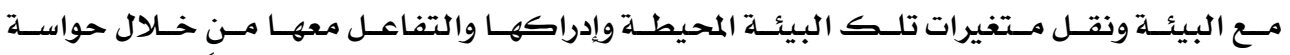

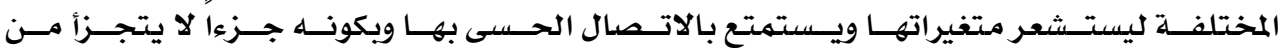

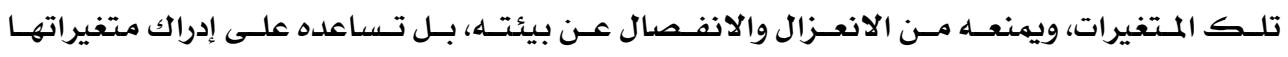

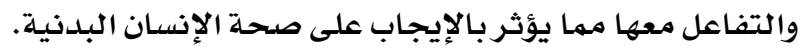

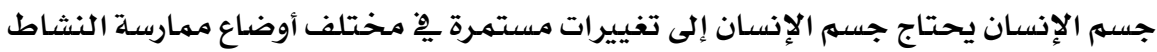

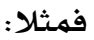

نشاط الجلوس يرى الباحثون أن الاختلاف يِّ أوضاع الجلوس يسبب الراحة للجالس. ب أما

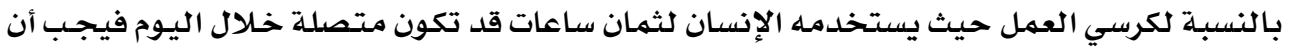

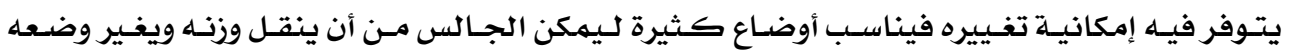

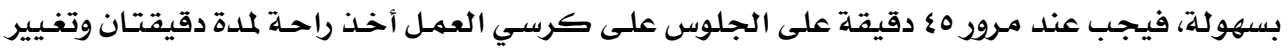

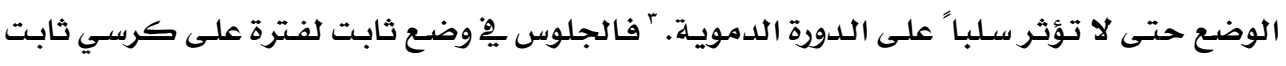

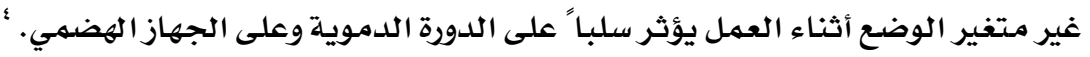

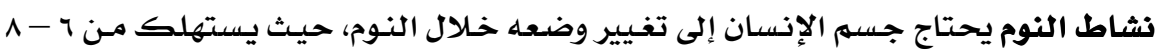

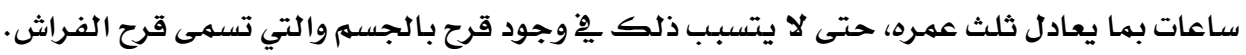

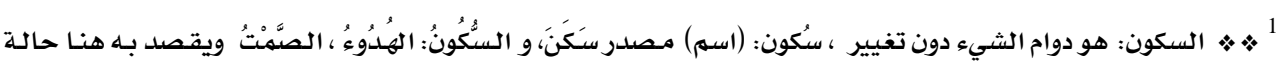

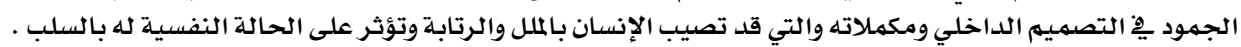

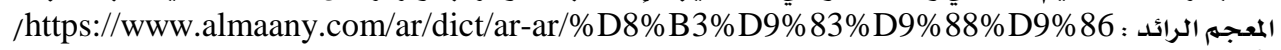

http:/www.ergo-eg.com160.php

2 مركز معلومات إرجونومية التصميم: التحليل البييوميكانيكي للعمل والمنتحجات

${ }^{3}$ Occupational health : computer health , imperial collage ,London :

Http:/www3.imperial.ac.uk/occhealth/guidanceandadvice/computerhralth/compute rhealthgeneralguidance

${ }^{4}$ Office furniture design according to human anthropometric date :

http:/www.designsociety.org/puplication/29654/office_furniture_design_according_t o_a_human anthropometr(ic_date ، 
فالتغيير يجعل الفرد يتمتع بالعمليات الحيوية السليمهة لوظائف جسمه فيتمكن الفرد مـن

أداء أنشطته اليوميلة ويكون قادر على الإنجاز مـع استغلال أكثر للوقت والجهد .

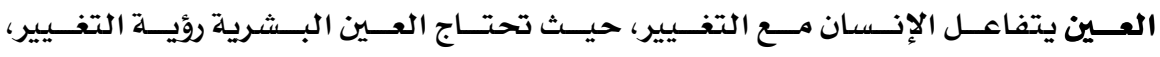

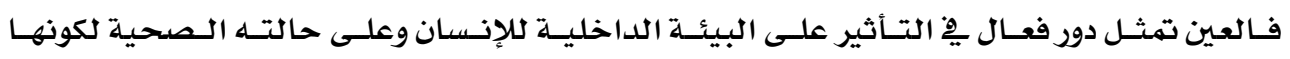

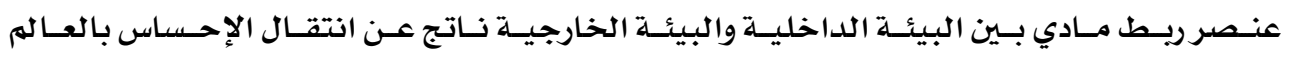
الخارجي يخ شكل موجات ضوئية وتحويلها إلى ذبذبات عصبيـة تصل إلى المخ.

يتزامـن مـع تغير الضوء بـين النور والظلام خلال سـاعات اليـوم حيـث يقوم الإنسـان بأنشطته

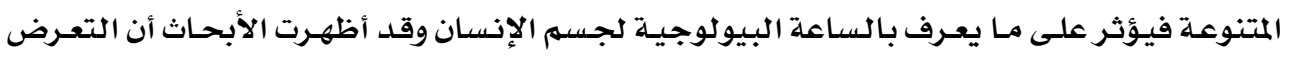
للضوء بأثكال مختلفة ويٌ أوقات مختلفة هي أحد العوامل التي تؤثر على كفاءة الأفراد وذلك من

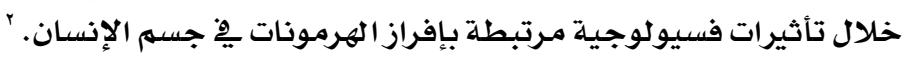

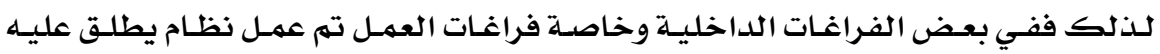

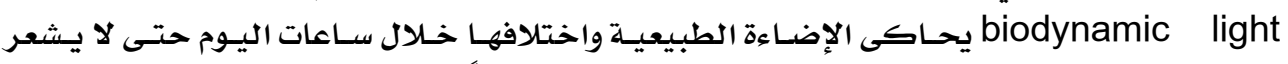
الإنسان بانفصاله عن البيئة المحيطة داخل فراغات العمل وأيضاً تأثير اختلاف الضوء على الموظفين خلال سـاعات العهل بالإيجاب على صحتهـم.

حيـث تـؤثر الإضـاءة الطبيعيـة على الغــد الـصنـوبريـة والنخخاميـة الـتي تقـع خلـف العـين والغدتين كلاهما حساس للضوء ومسئول عن تنظيم إفراز الهرمونات التي تعمل على تنظيم الوقت

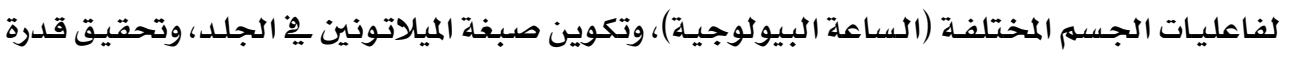

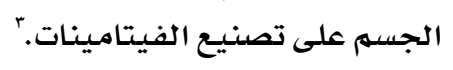

وأكد مؤتمـر الآثار العضوية للضوء الذي أقامته أكاديمية العلوم يِ نيويـورك والذي أثبـت

أن الضوء يِ البيئـة يحقق العديد من الآثار العضويـة التي تحقق الصحة وتؤثر على الرؤيسة التي لها

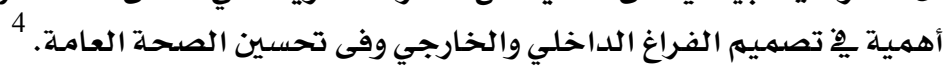

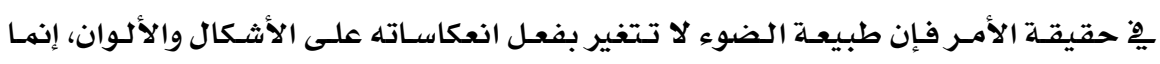

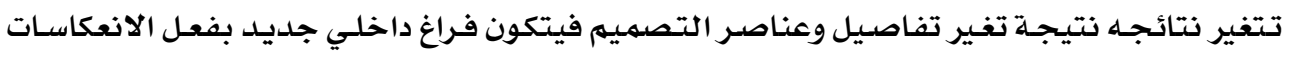
والظلال المتكونة والتي تتغير بتغير الزمن، كها ترتبط مـلامس الأسطح بالضوء السـاقط عليها حيث يمكن التعرف عليها بصرياً عن طريق سلوك الأسطح يْ التعامل مـع الضوء الساقط عليها.

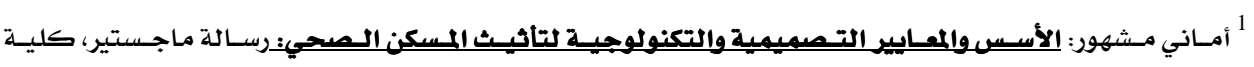

${ }^{2}$ Lguzzini: biodynamic light

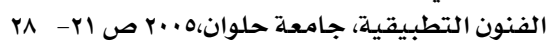
http://www.iguzzini.com/download/ricerche/annex45_2008.pdf 3 عبد الرحمن محمد بكر: البيئة الضوئية داخل المسكن وأثرها على صحة الإنسان، مجلة علوم وفنون، المجلد ·ب، العدد ا،

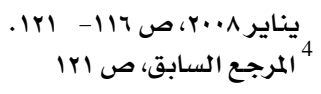


لعبت الإضاءة الطبيعية المتغيرة عبر الزمن وانعكاسـاتها على الفراغـات الداخليـة دوراً مهماً

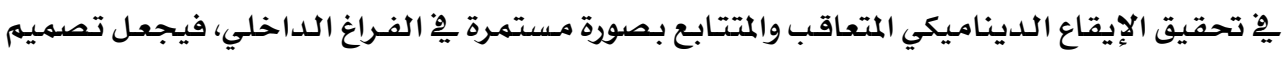

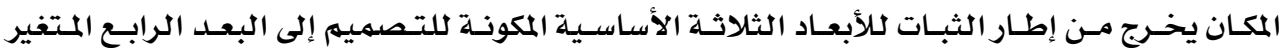

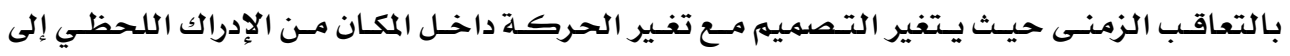

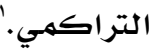

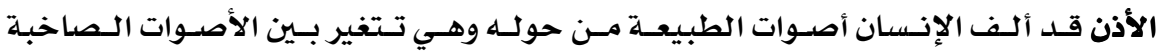

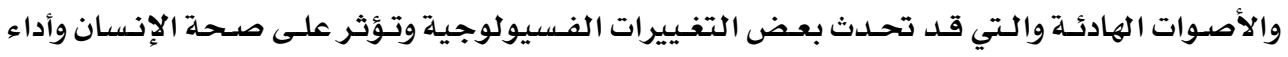

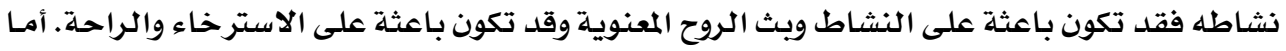

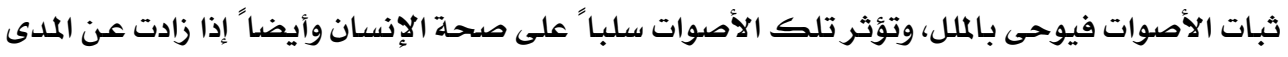

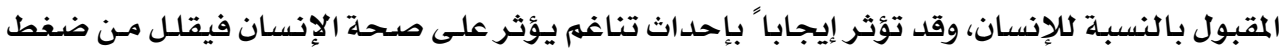
الدمويساعد على الهدوء.

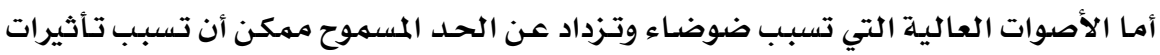

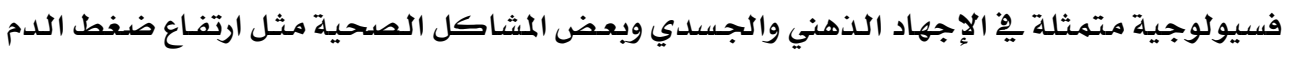

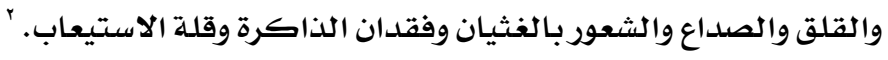

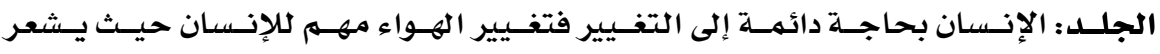

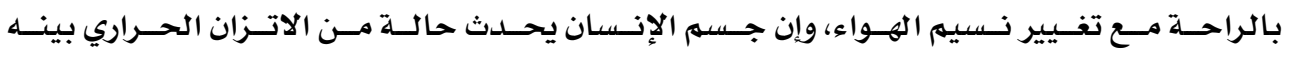

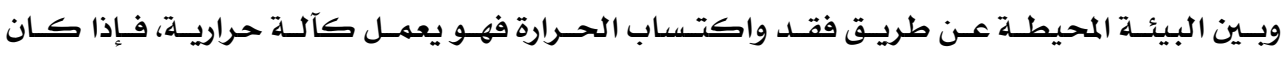

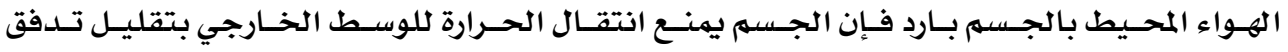

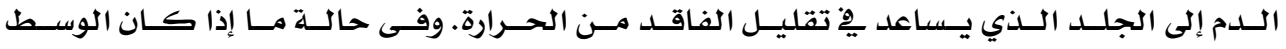

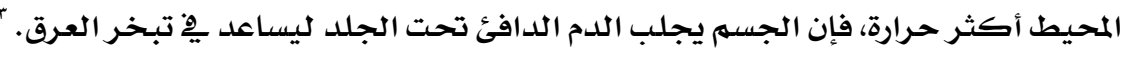

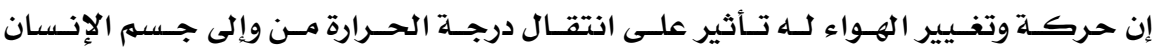

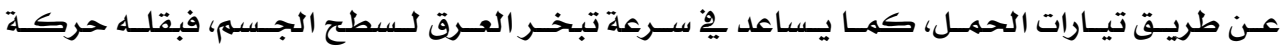

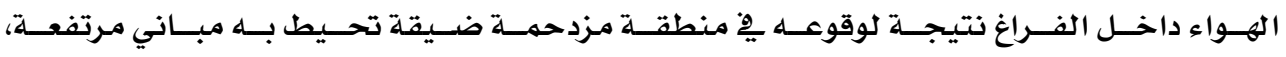

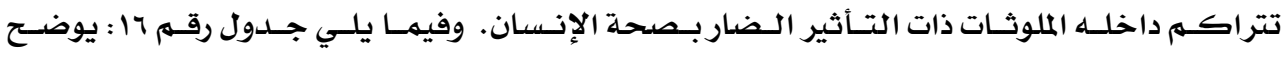

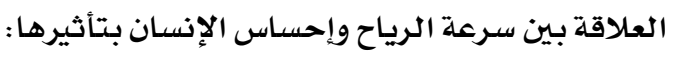

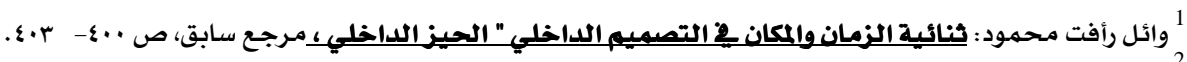

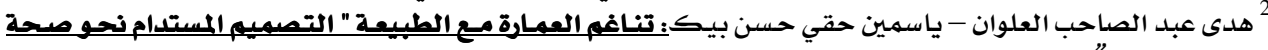

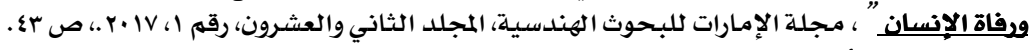

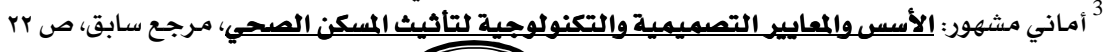




\begin{tabular}{|c|c|}
\hline تأتُّرها على الإنسان & سرعة الرياح م/ث \\
\hline 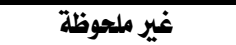 & $\cdot$, ro_. \\
\hline محببة & $\cdot, 0-\cdot$, ro \\
\hline الحرص من تأثير الهواء & $1, \cdot \cdot-\cdot, 0$ \\
\hline مثير للضيق & $1,0-1, \cdot \cdot$ \\
\hline مزعجة & أعلى من 1,0 \\
\hline \multicolumn{2}{|c|}{ جلدول 14: يوضح العلاقة بين سرعة الرياح وإحساس الإنسان بتأثّيرها } \\
\hline
\end{tabular}

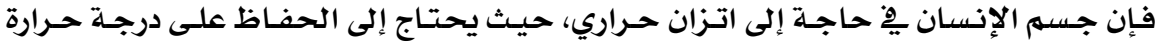

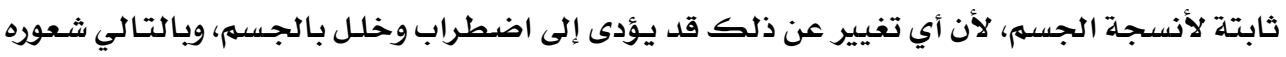

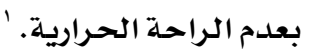

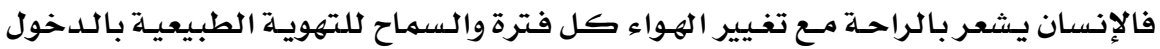

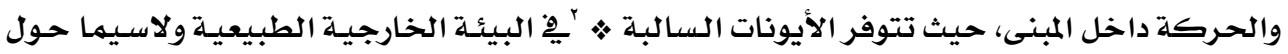

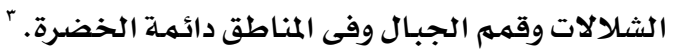

العقل البشرى: إن الإنسان يحتاج إلى طاقة للتفكير، ولا يهكن للإنسان أن يطور فكره إلا إذا

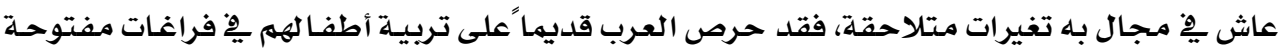

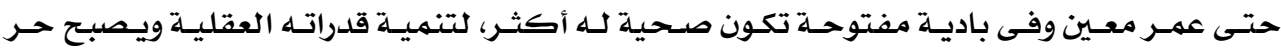

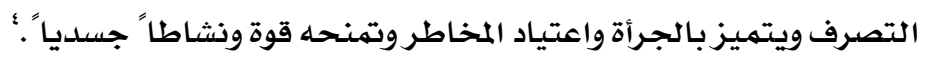

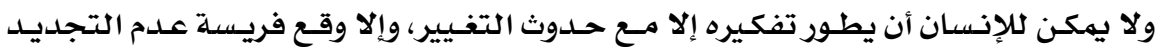

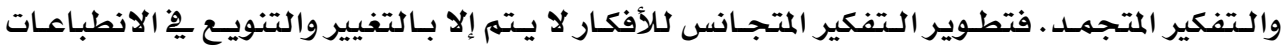

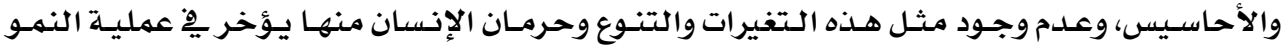

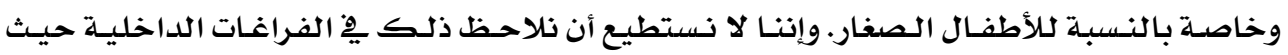

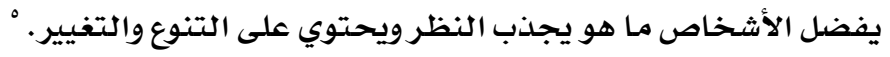

1 محمد عبد الفتاح أحمد العيسوي: تأثير تصميم الغلاف الخارجي للمبني على الاكتساب الحراري والراحة الحرارية

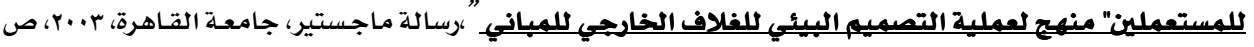

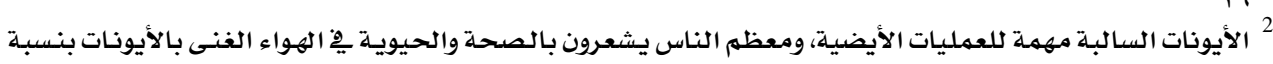

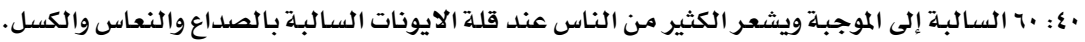

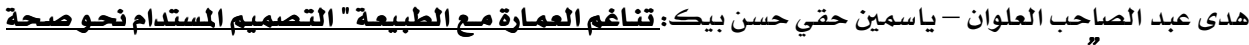

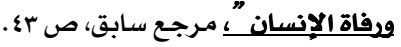

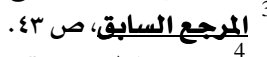

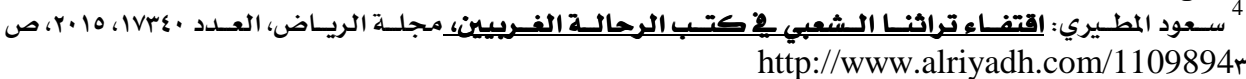

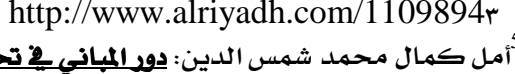

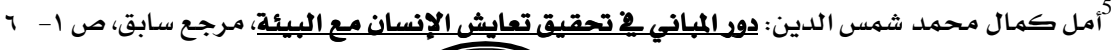


- ثانياً: تأثير التناغم بين التفيير والسكوز على الصحة النفسية للإنسان:

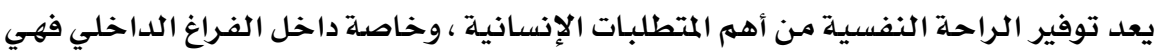

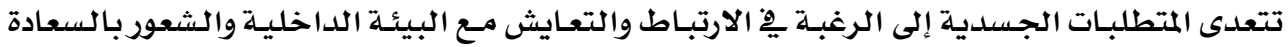

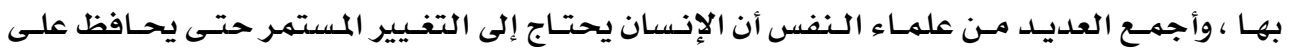

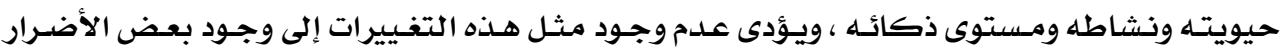

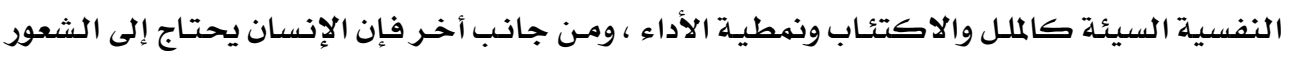

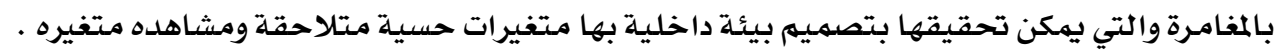

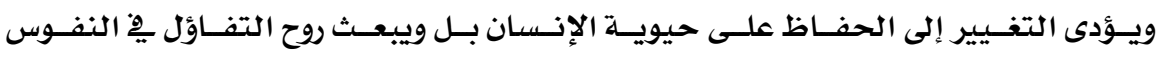

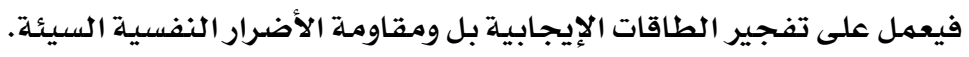

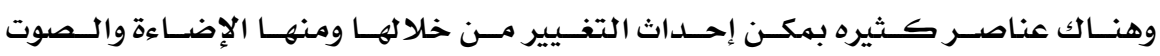

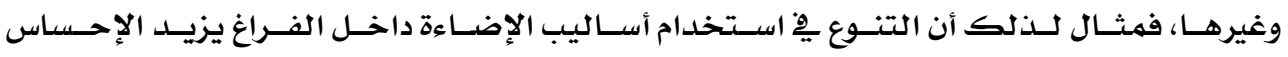

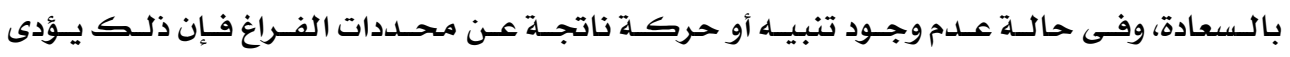

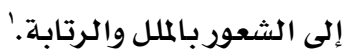

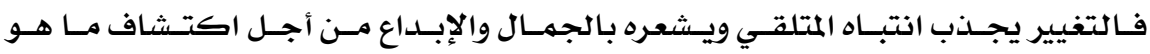

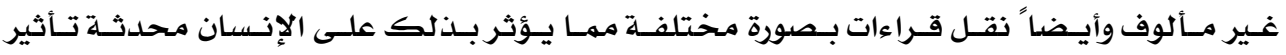

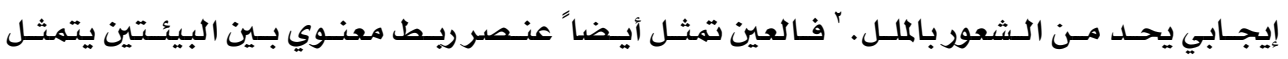

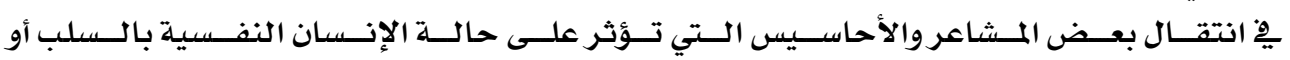

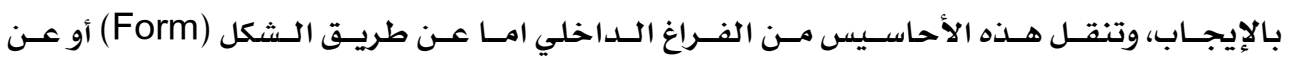
طريق اللون ونسبة الإضاءة الساقطة علئه الاحسيس.

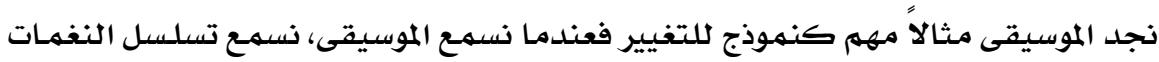

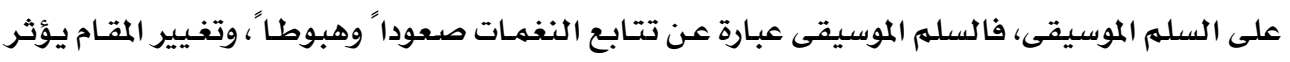

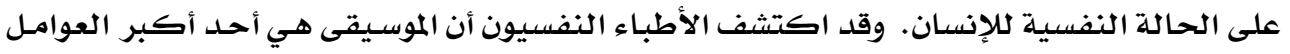

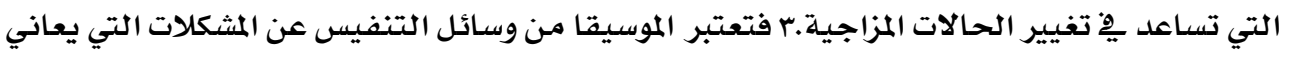

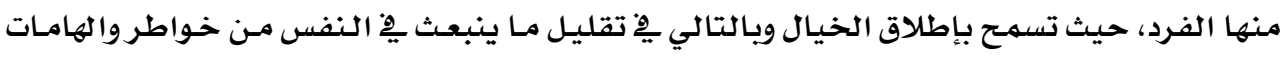

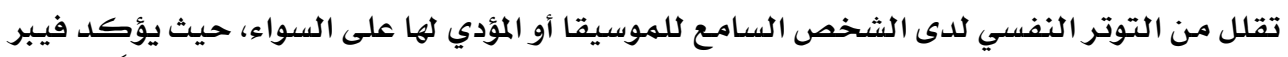

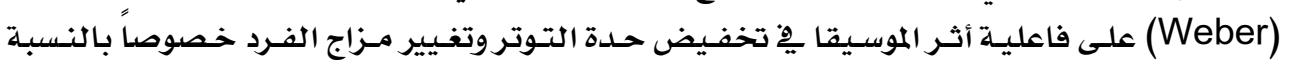

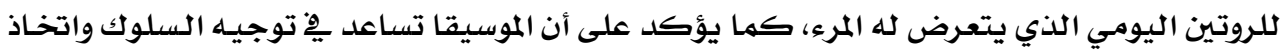

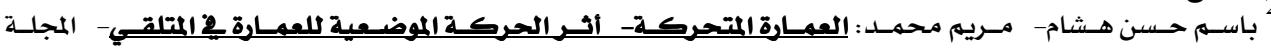

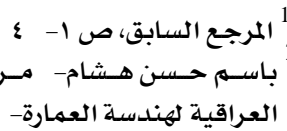

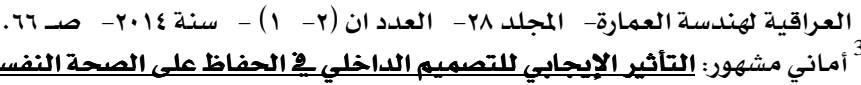

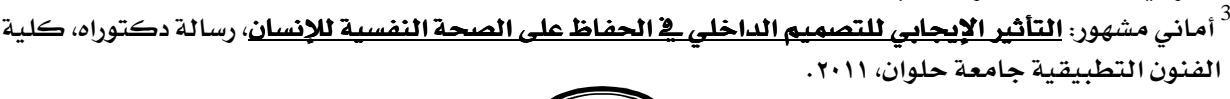




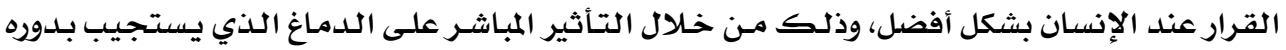

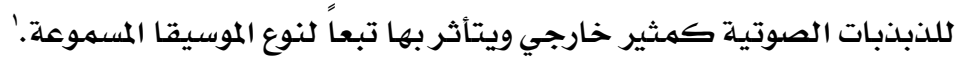

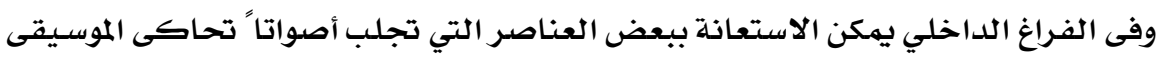

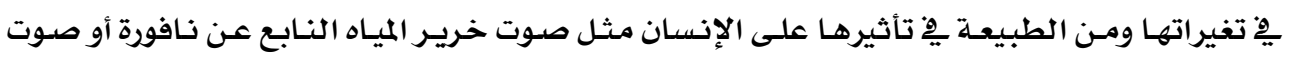

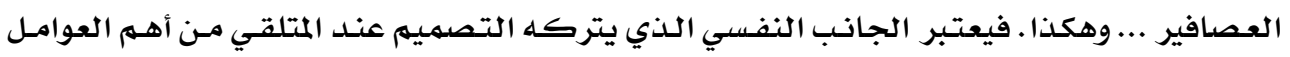

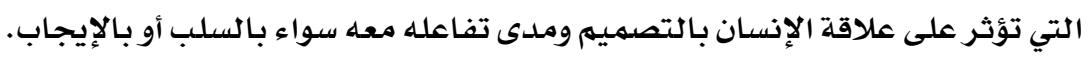

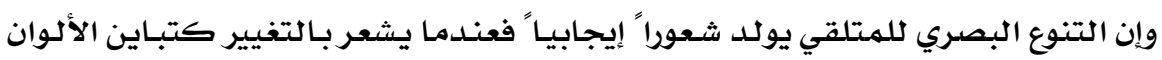

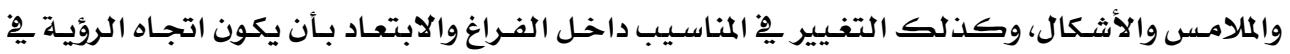

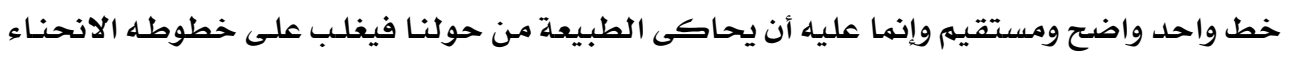

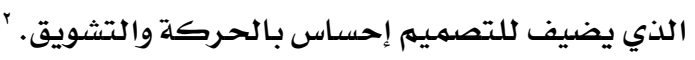
- ثالثاً : تأثير التناغم بين التفيير والسكون على سلوك الإنسان: عندما يتصل الإنسان بالبيئة المحيطة يتعرض لعدد من المثيرات الصادرة عما يحيط به وقد

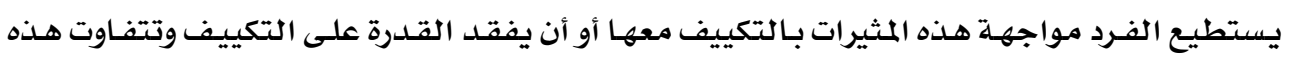

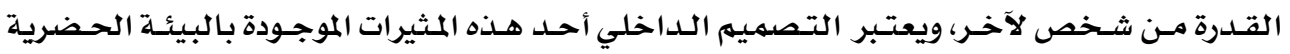

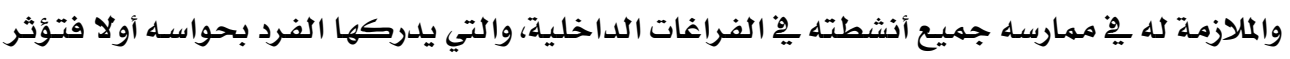
على سلوكياته.

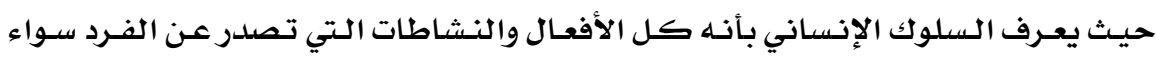

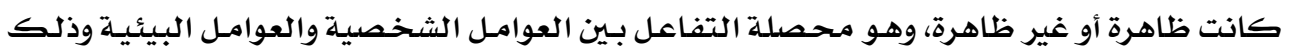
وفقاً لقدرات الفرد وطريقة إدراكه.

فالإدراك هو الوسيلة التي يتصل بها الإنسان مـع بيئتسه المحيطة، فهو عمليـة عقليـة تتم بها

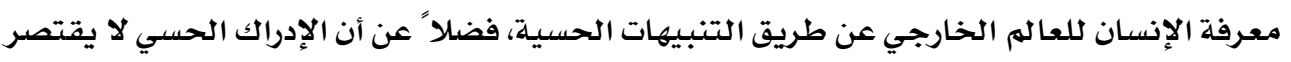

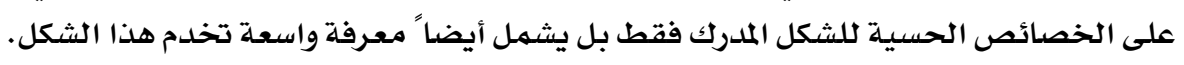

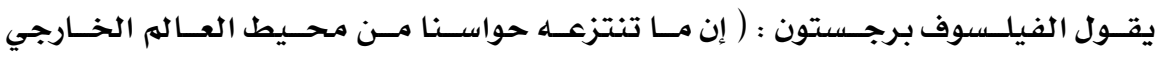

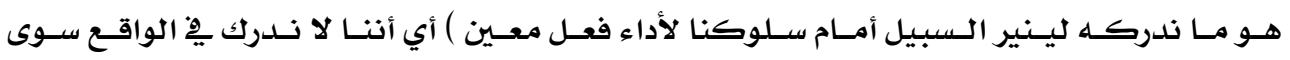

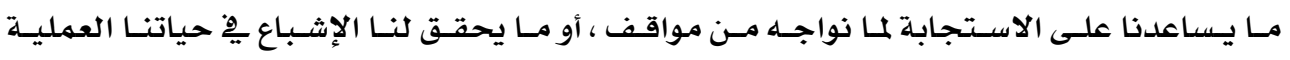

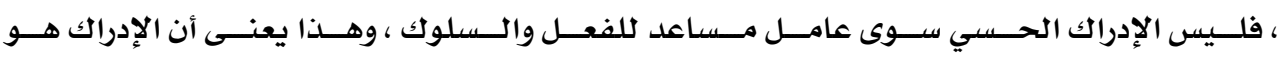

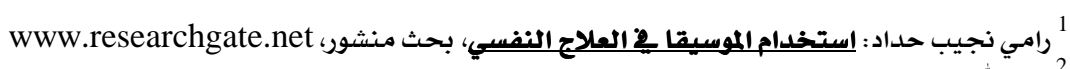

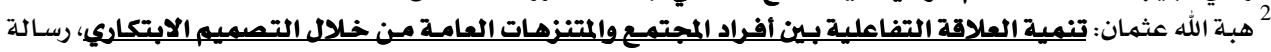

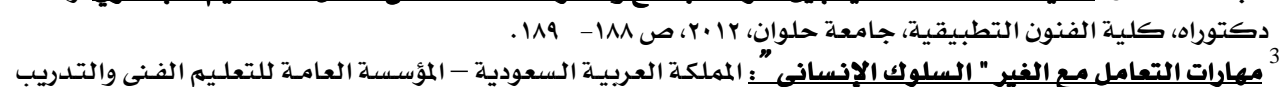
http://www.booksjadid.top/2013/04/pdf_9102.html

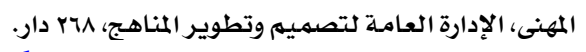
https://ia801704.us.archive.org/24/items/133-161tanmia.booksjadid.blogspot.com/175.zip 


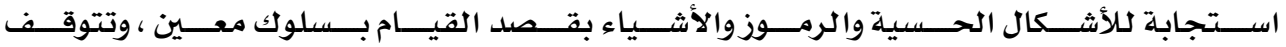

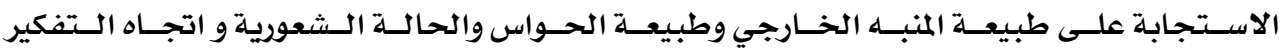

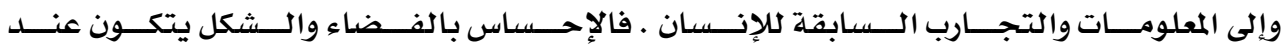

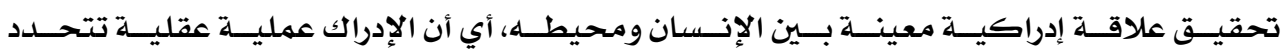

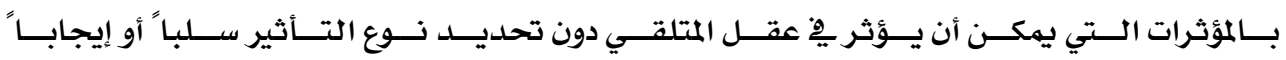

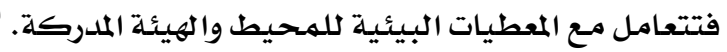

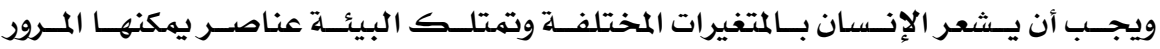

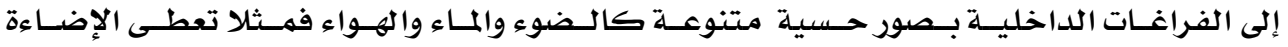

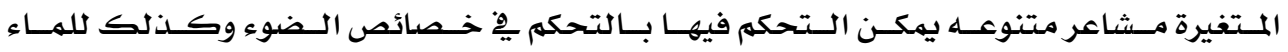

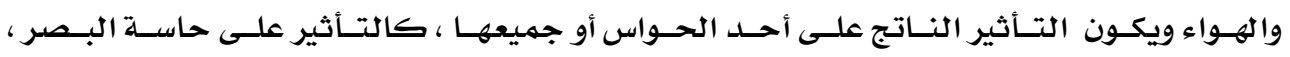

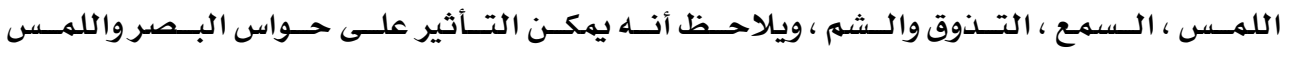

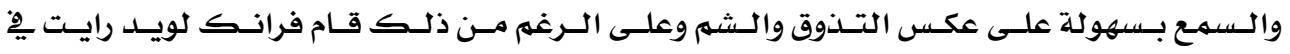

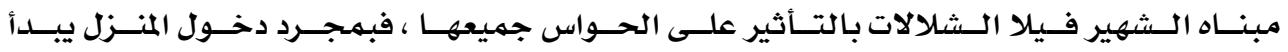

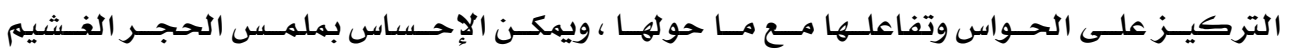

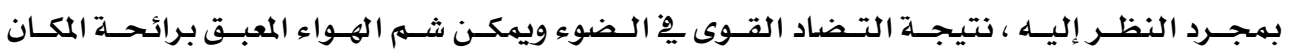

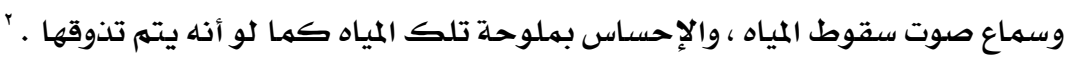

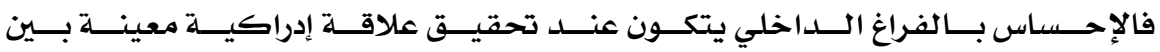

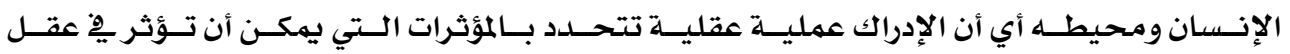

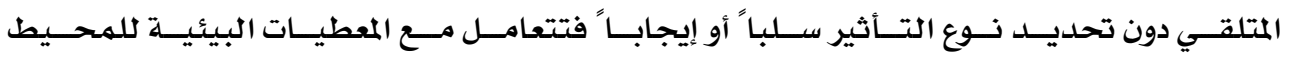

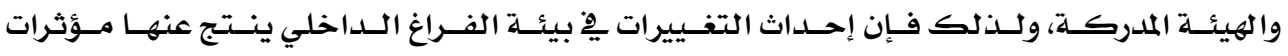

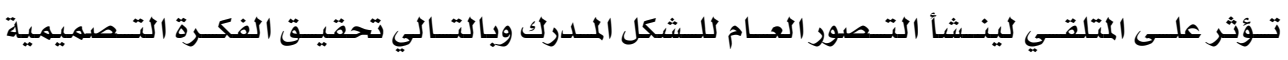
المطلوبة. تجونج

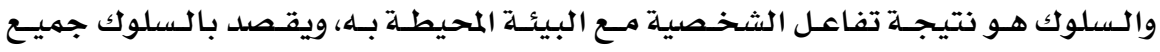

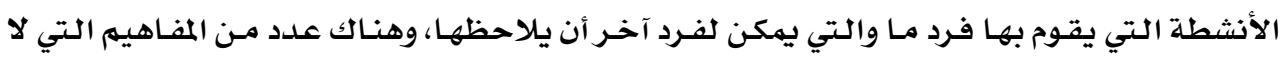

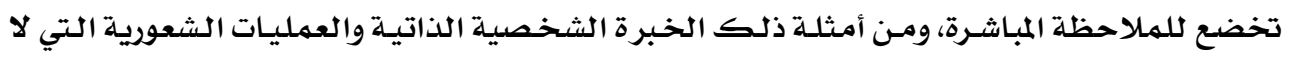
يمكن للغير أن يلاحظها.

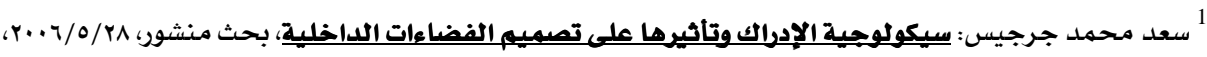
https://www.iasj.net/iasj?func=fulltext\&ald=36929

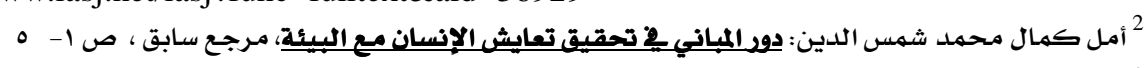

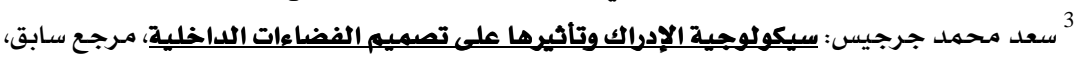
https://www.iasj.net/iasj?func=fulltext\&ald=36929 
ويتأثر سـلوك الإنسان بالبيئسة المحيطـة والتغسيير فيها وبالتـالي فهو يتأثر بترتيـب البيئسة

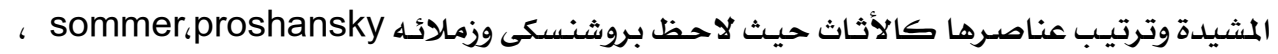

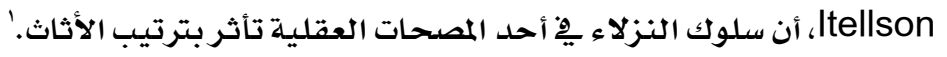

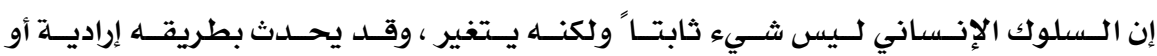

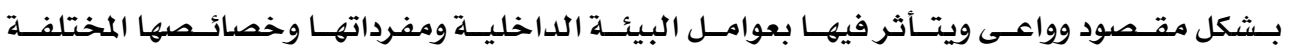

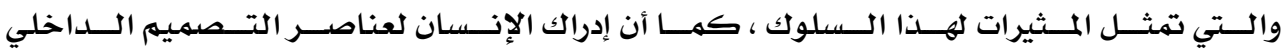

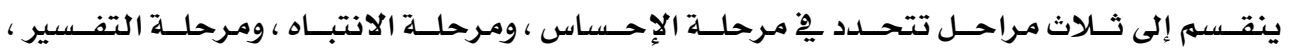

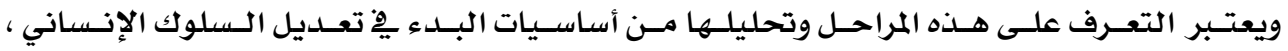

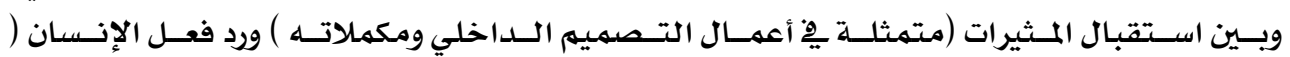

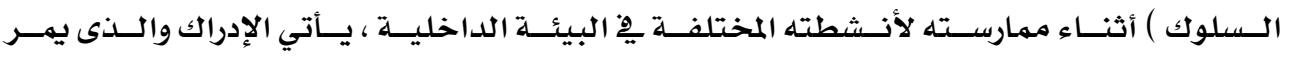

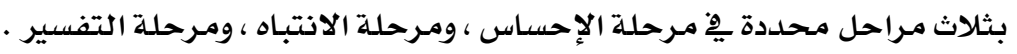
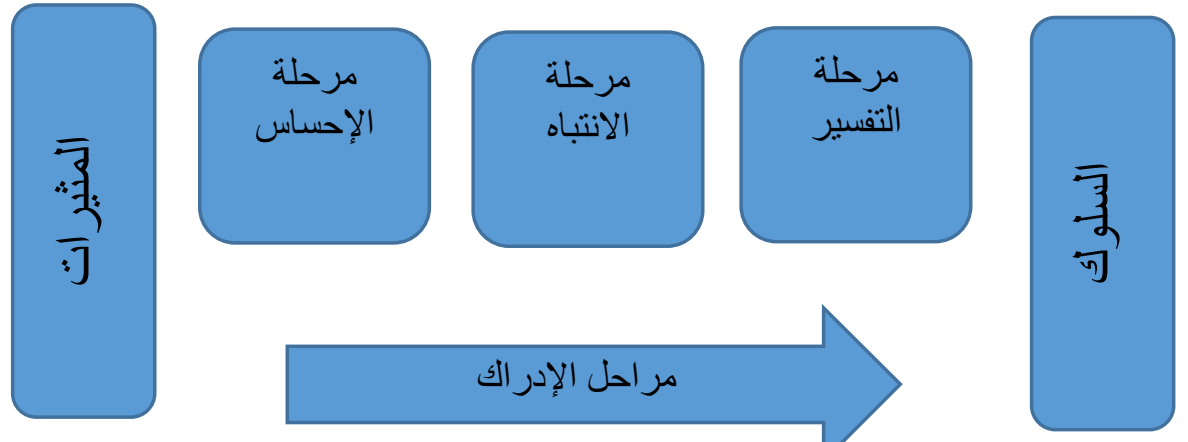

مر احل الإدر الك

شكل V : يوضح مراحل الإدراك بين استقبال المثيرات واستجابة الإنسان (السلوك)' و

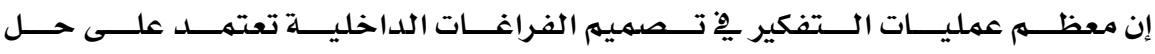

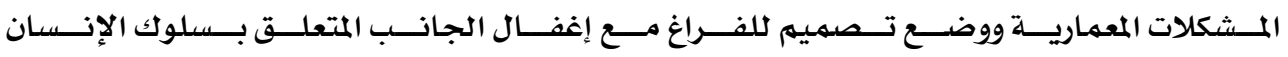

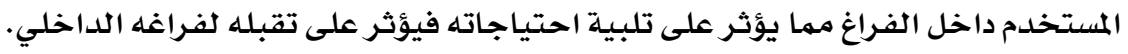

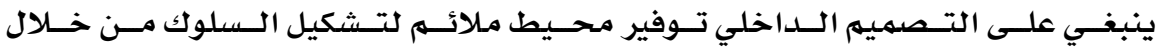

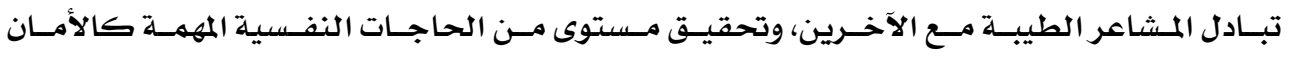

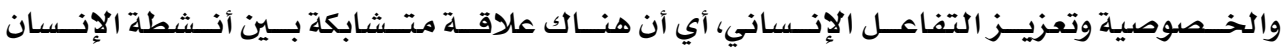

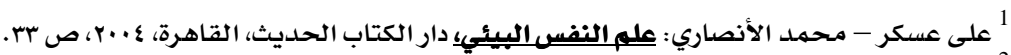

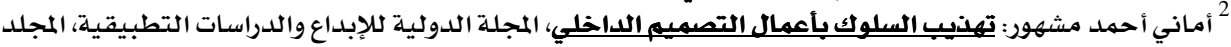
الثامن عشر، العدد الثاني أكتوبر، 
chuman activities عليه تغير الثانية.'

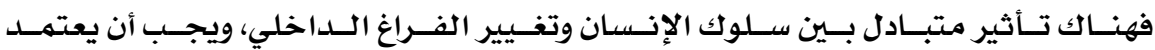

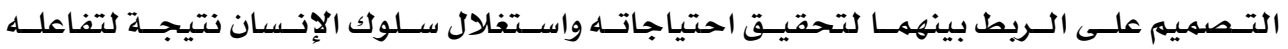

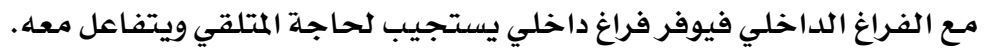

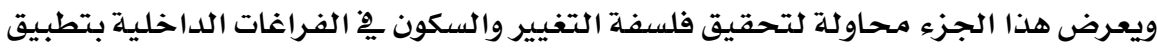

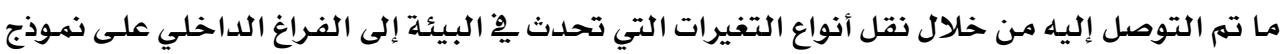

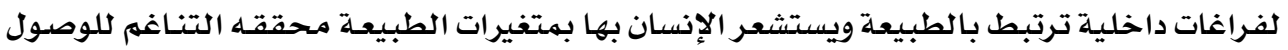

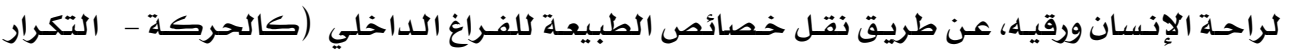

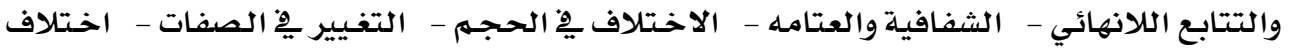

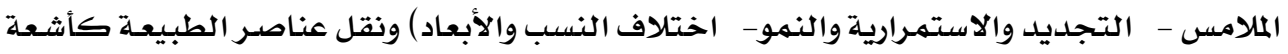

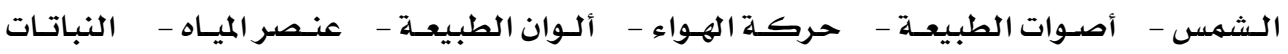

$$
\text { ومفردات الطبيعة. }
$$

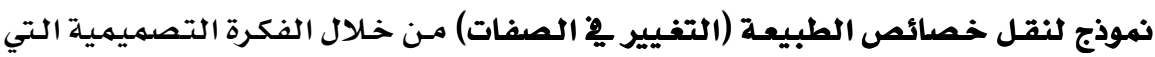

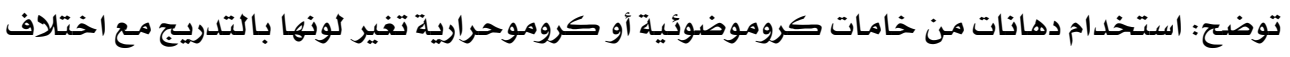

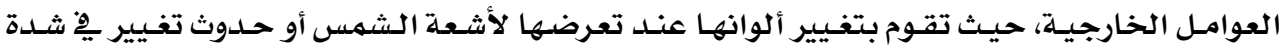

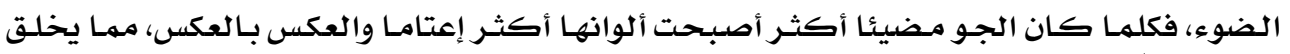

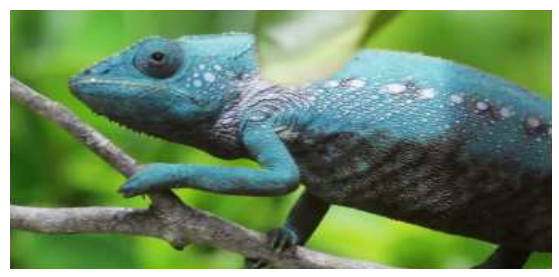

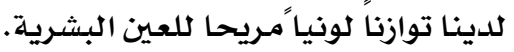
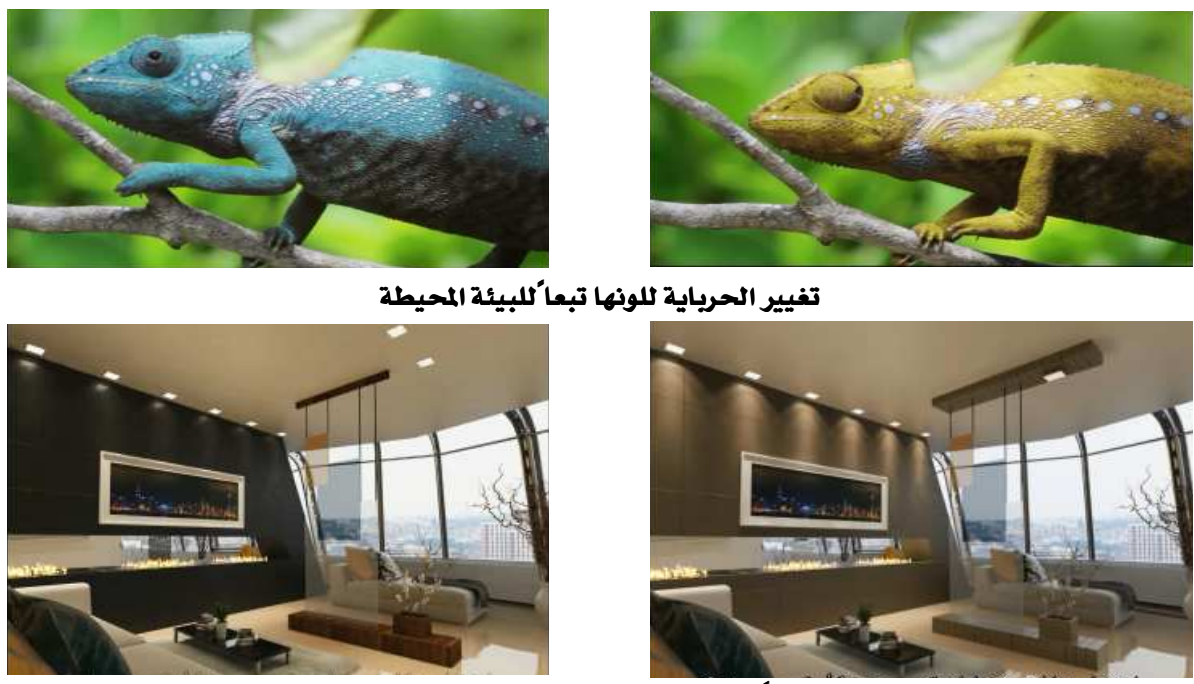

تغيير الحرياية للونها تبعا للبيئة المحيطة

تغيير لون الدهانات تدريجياً عند تعرضها لأثعة الشمس أو حدوث تغيير فِ شدة الضوء

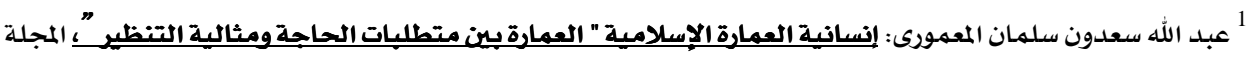

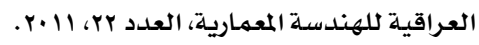


- نهوذج لنقل عناصر الطبيعة (عنصر المياه):

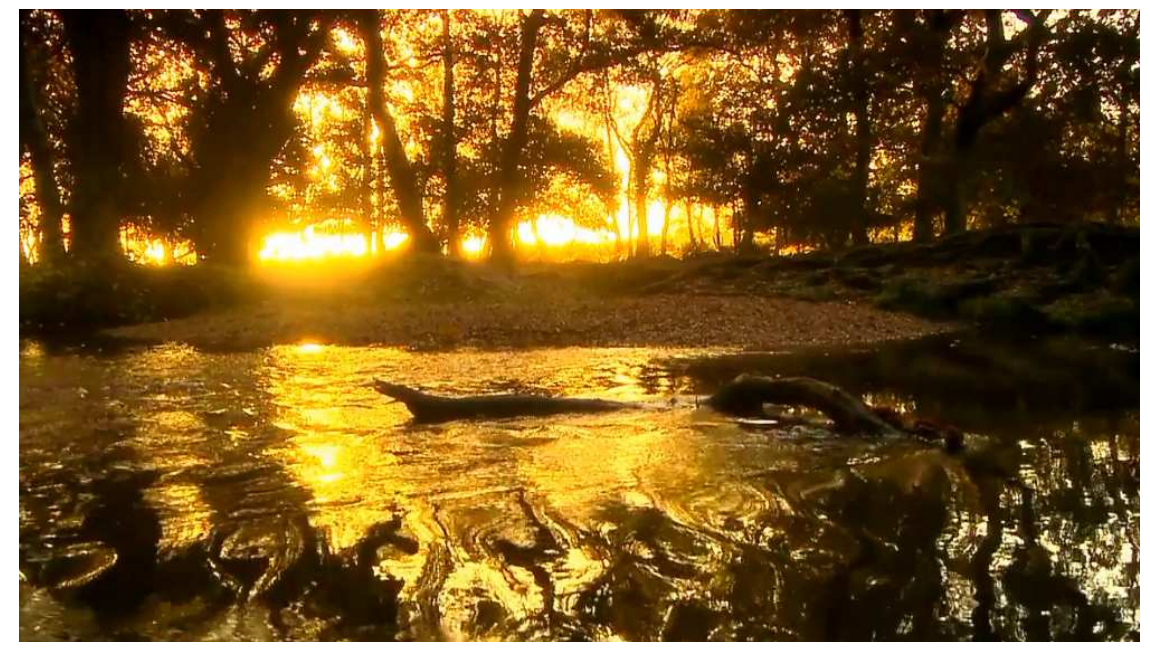

الاستفادة من وجود عنصر المياه يِ الطبيعة

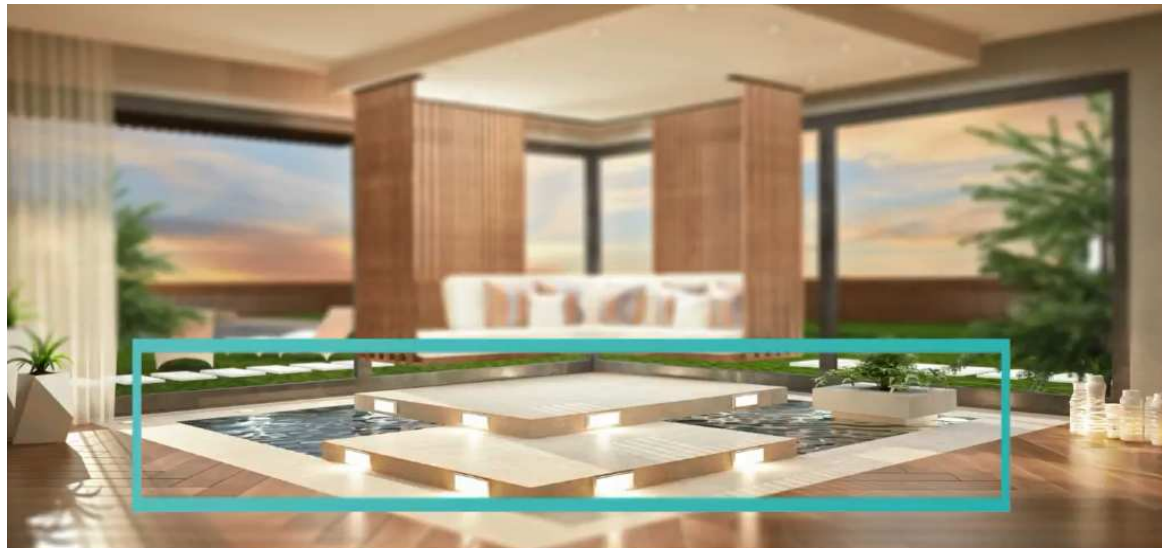

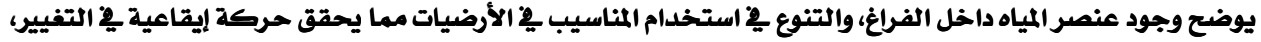
وأيضاً الإحساس بالسكون يْ الأرضيات الثابتة. 
- نقل عناصر الطبيعة (عنصر النبات):
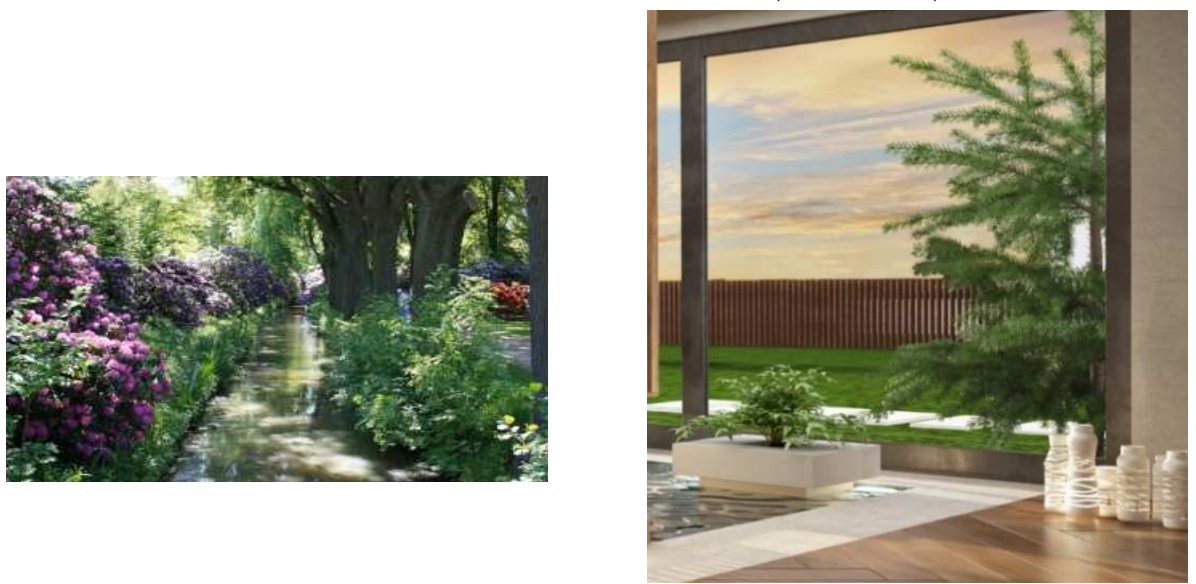

التنوع والاختلاف يِ شكل النباتات يِّ الفراغ الداخلي، واستخدام الأنواع المختلفة التي تضفي روائح ذكية تنتشر مـع نسيم الهواء وتؤثر بِ الحالة النفسية للإنسان

- نقل عناصر الطبيعة (حركة الهواء):

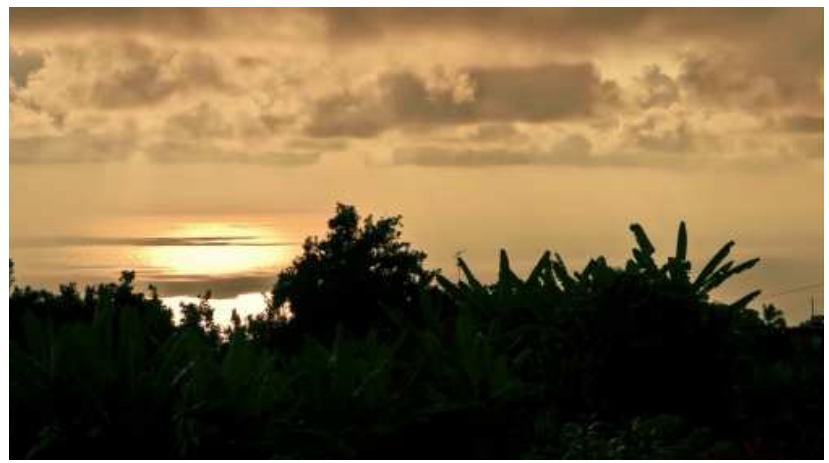

نقل حركة الهواء من خلال توجيه الفراغ الداخلي بحيث يتحرك الهواء

بلطف داخل الفراغ واستخدام ستائر ذو خامات مختلفة المسامية تتحكم دخول الهواء كأنه نسيم هواء محبب للإنسان.

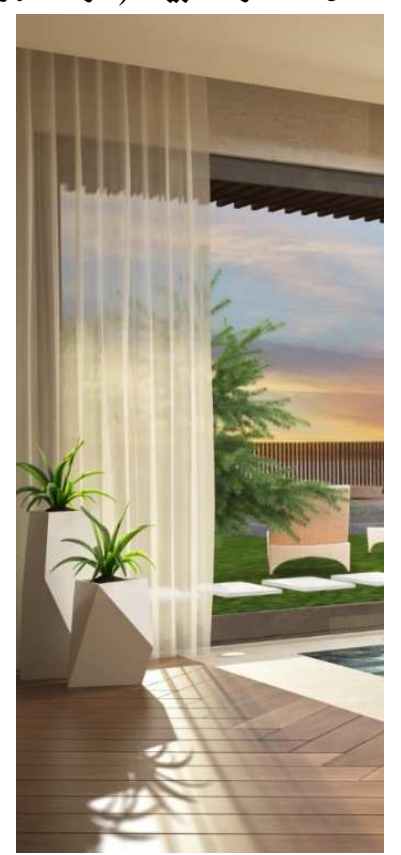




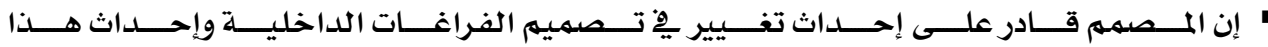

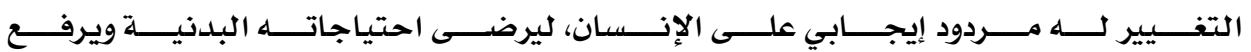

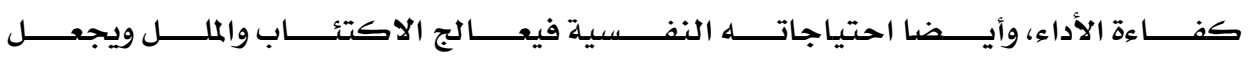

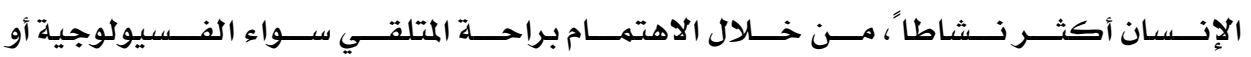

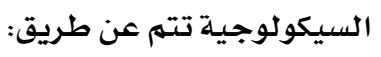

أولا: البلدنية /الفسيولوجية:

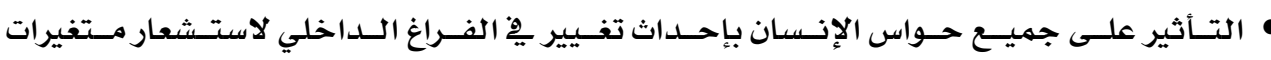

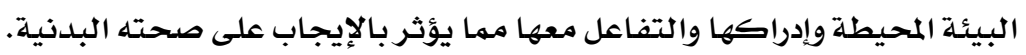

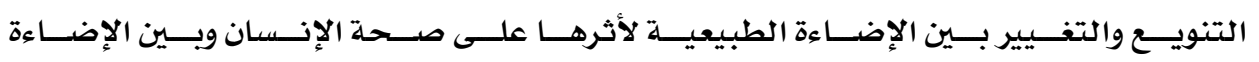
الصناعية للتأثير على كفاءة الفرد الأدائية.

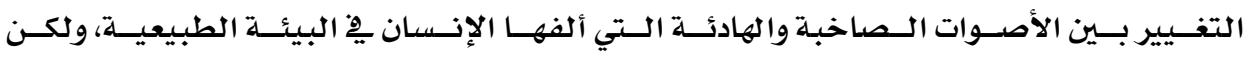

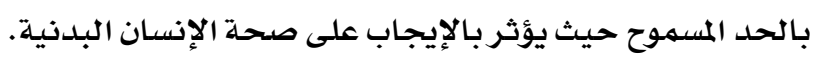

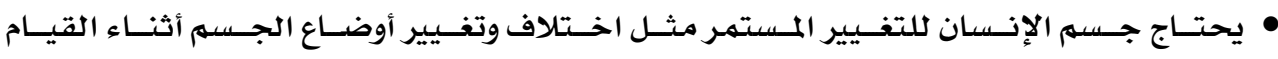

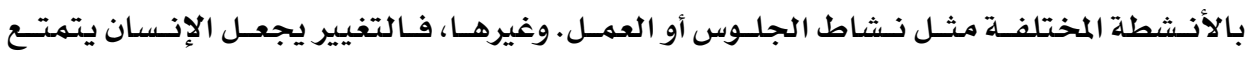

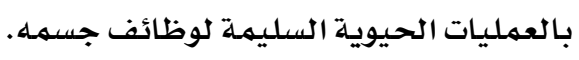

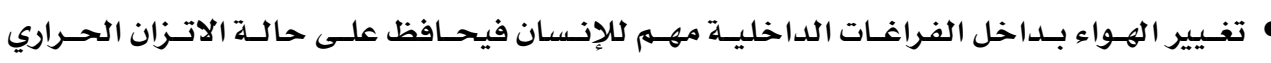

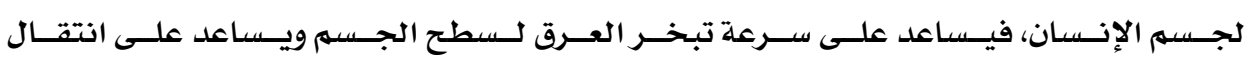

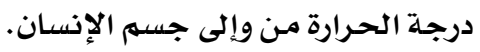

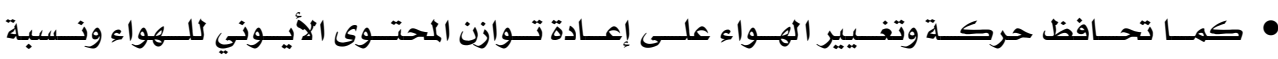

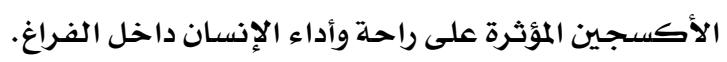

ثانياً : النفسية /السيكولوجية:

ه التنوع يِّ استخدام أساليب الإضاءة داخل الفراغ حيث يذيد الإحساس بالسعادة.

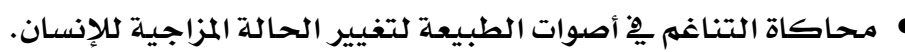

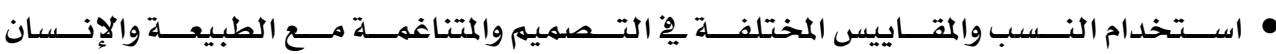
لتحقيق تصميهم مـريح نفسياً للإِنسان.

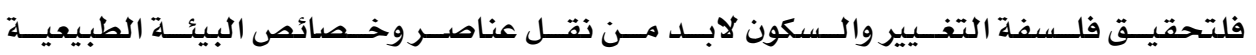
بالفراغات الداخلية.

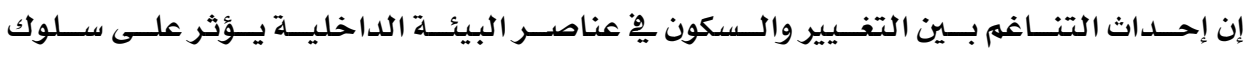

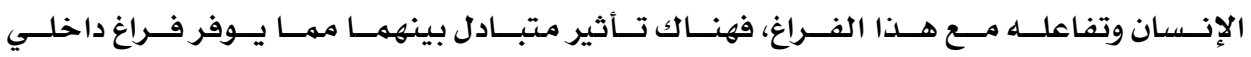

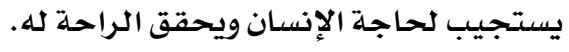


1) أحمد سمير - دينا فكرى: ثقافة التغييير كحافز إيداعي 2ح التصميم الداخلي، التصميم الدولي، عدد ه،

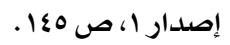

r ) أمـاني مشهور: الأسـس والمعابير التصميمية والتكنولوجيـة لتأثيث المسكن الصحي: رسالة ماجستير،

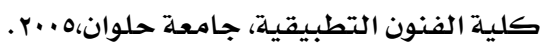

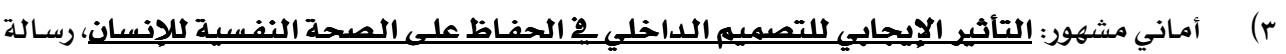

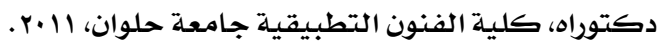

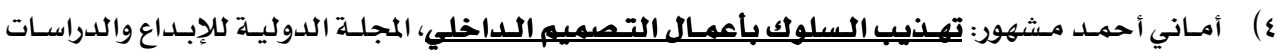

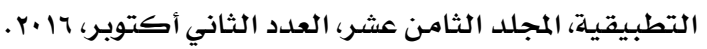

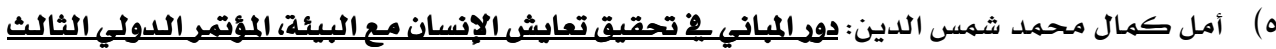

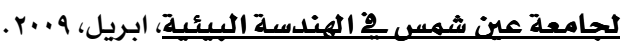

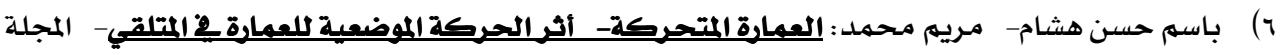

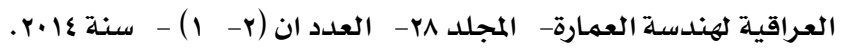

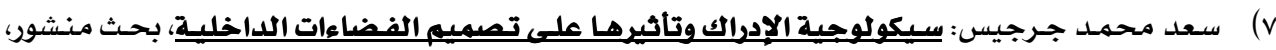
r.. https://www.iasj.net/iasj?func=fulltext\&ald=36929

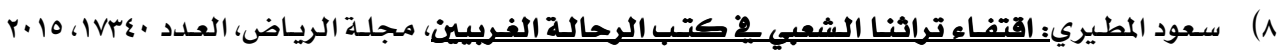
http://www.alriyadh.com/1109894

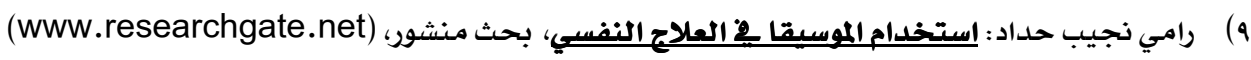

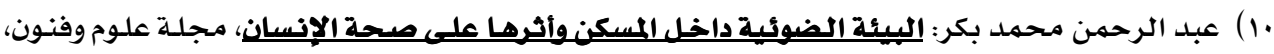

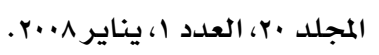

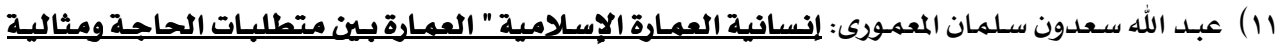

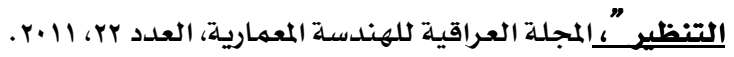

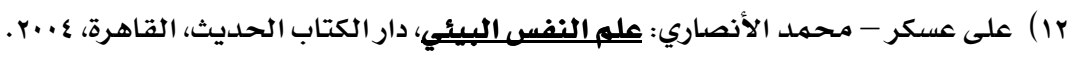

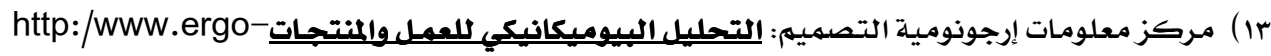
eg.com160.php

عا ) محمد عبد الفتاح أحمد العيسوي: تـأثير تصميم الغـلاف الخـارجي للمبنى على الاكتساب الحـرادي

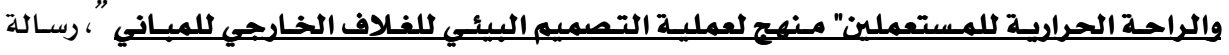

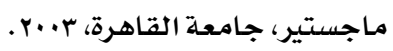

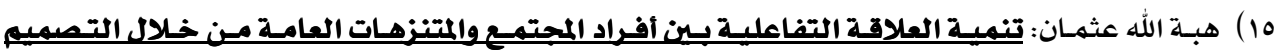

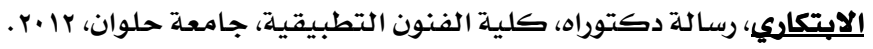

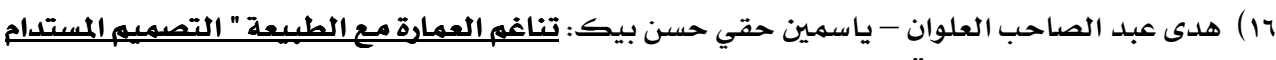

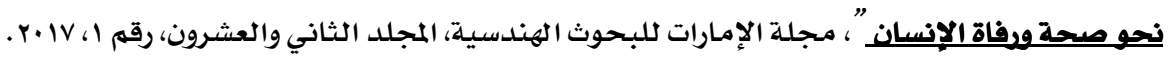




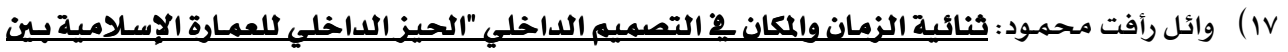

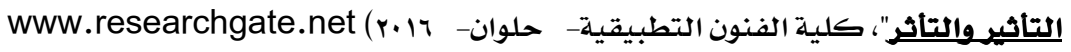

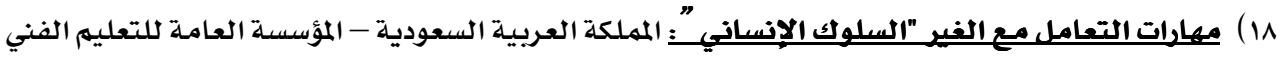

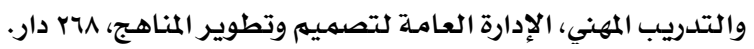

http://www.booksjadid.top/2013/04/pdf_9102.html

https://ia801704.us.archive.org/24/items/133-161tanmia.booksjadid.blogspot.com/175.zip

19) Occupational health : computer health, imperial collage,London :

Http:/www3.imperial.ac.uk/occhealth/guidanceandadvice/computerhralth/computerhea lthgeneralguidance

20) Office furniture design according to human anthropometric date :

http:/www.designsociety.org/puplication/29654/office_furniture_design_according_to _a_human_anthropometr (ideate ،

21) Lguzzini: biodynamic light

http://www.iguzzini.com/download/ricerche/annex45_2008.pdf 


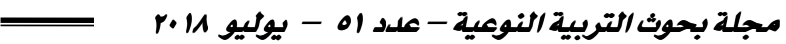

\section{The harmony Effect between Changeability and Steadiness on Human in the Interior Spaces}

\section{Abstract}

Human always needs the sense of connection with and belonging to the surroundings. This feeling is generated by the constant sense of environmental variables; and with the fact that the environment is always variable, the characteristics of stillness spaces prevent the comfortable coexistence of human inside because of the constant changes in the environment around him/her, and it feels like living in closed boxes. Human lives within the spaces with an average of $90 \%$ of his/her life until they become spaces with a static design that does not compatible with the rapidly change of humanity dynamic nature.

The research problem can be determined in the loss of human correlation with the environment, which adversely affects his/her physical and psychological health. Thus, Is the interior designer capable of making changes in the interior design spaces to simulate the change and diversity in the natural environment through interior design elements? How is the effect of harmony between changeability and steadiness in the elements of internal environment on human behavior and performance of his/her activities within the interior Space?

The research aims to predict what beyond the changeability and steadiness in the relationship between the internal spaces of the environment and its impact on human health inside the interior space. Besides, the impact of change in interior design on human behavior and performance of various activities, through studying the impact of change and stillness on human behavior and performance of his/her activities within the interior Space, through survey and analytical studies.

Keywords: - Change - Steadiness - Interior space -Psychological and physical comfort. 